Marquette University

e-Publications@Marquette

$3-1-2011$

Examining the Content of Mental Health Intake Assessments From a Biopsychosocial Perspective

Lari Meyer

Marquette University

Timothy P. Melchert

Marquette University, timothy.melchert@marquette.edu

Post-print. Journal of Psychotherapy Integration, Volume 21, No. 1 (March 2011), DOI.

This article may not exactly replicate the final version published in the APA journal. It is not the copy of record. 


\title{
Examining the Content of Mental Health Intake Assessments from a Biopsychosocial Perspective
}

\author{
Lari Meyer \\ Department of Counselor Education and Counseling Psychology, \\ Marquette University \\ Milwaukee, WI \\ Timothy P. Melchert \\ Department of Counselor Education and Counseling Psychology, \\ Marquette University \\ Milwaukee, WI
}

\begin{abstract}
Psychotherapists' approach to intake assessment has a major impact on mental health case conceptualization and treatment. Despite the importance of this issue, very little is known about the actual intake assessment practices of therapists providing mental health care in the community. This appears to be the first study that has investigated which aspects of biological, psychological, and sociocultural functioning are documented by therapists in their client intake assessments, how thoroughly these issues are assessed, and how well the information collected is then integrated into the assessment findings and case conceptualization. The examination of 163 client files from 3 mental health clinics found that therapists were regularly collecting client information regarding a wide range of biopsychosocial issues, though not in a detailed or comprehensive manner. There was also little evidence that the information was being integrated in a manner designed to maximize treatment effectiveness. These findings have major implications for training and practice in mental health assessment.
\end{abstract}


NOT THE PUBLISHED VERSION; this is the author's final, peer-reviewed manuscript. The published version may be accessed by following the link in the citation at the bottom of the page.

Intake assessment is a critical component of mental health treatment. The amount and type of information that is collected during the intake process and the way that information is then analyzed and integrated directly impacts assessment and diagnostic findings, case conceptualization, and the subsequent course of treatment. Therefore, the approach that psychotherapists take toward intake assessment is of critical importance in mental health treatment.

One of the most comprehensive, integrative, and well known approaches to conceptualizing the mental health assessment process is the biopsychosocial (BPS) approach. This approach consequently provides a useful framework for examining therapists' assessment practices. The BPS approach stresses the importance of a comprehensive, systemic perspective on human development and functioning and emphasizes a holistic integration of biological, psychological, and sociocultural factors when attempting to understand human psychology. Though a BPS approach to mental health practice was presented as early as 1917 as part of the psychiatry curriculum at Johns Hopkins School of Medicine (Meyer, 1917), it was first fully articulated by Engel (1977) in reaction to the prevailing biomedical approach that dominated medicine at that time. Engel argued that by restricting their views on patients' illnesses as having only biological causes, physicians limited their ability to fully understand and effectively treat patients. The biomedical model excludes important psychological and sociocultural factors, and its reductionist approach fails to take into account the multiple interacting causal influences on disorders, instead favoring the perspective that there is a single cause to each illness.

The BPS approach is based on general systems theory (von Bertalanffy, 1950, 1968), one of the highly influential approaches to understanding complex natural phenomenal in the sciences. These approaches are now usually subsumed under the general category of nonlinear dynamical systems theory which is often referred to as complexity theory when examining the nature of more complex systems. The human mind and brain are certainly very complex systems, and general systems theory, the BPS approach, and complexity theory approaches have been very influential in recent conceptualizations of psychotherapy and human psychology in general 
NOT THE PUBLISHED VERSION; this is the author's final, peer-reviewed manuscript. The published version may be accessed by following the link in the citation at the bottom of the page.

(e.g., Anchin, 2008; Guastello, Koopmans, \& Pincus, 2009; Magnavita, 2008).

Integrative approaches to psychotherapy are often conceptualized along the lines suggested by Norcross (2005) who argued that they fall into the categories of technical eclecticism, theoretical integration, common factors, and assimilative integration. A more comprehensive perspective for understanding human development and functioning in general, however, is the BPS approach. This approach does not focus just on integrative approaches to psychotherapy. From this perspective, all of human psychology, including development, functioning, personality, psychopathology, psychotherapy and other behavior change processes, can only be understood by taking a comprehensive, integrative BPS approach (Anchin, 2008; Kaslow et al., 2007; Magnavita, 2008; Melchert, 2007). The BPS approach is then used to inform the whole treatment process from intake assessment through treatment planning, the implementation of treatments, and the assessment of treatment outcomes.

In the years following Engel's (1977) seminal article, the BPS approach became widely accepted for the conceptualization and treatment of a wide variety of mental and physical health problems (Suchman, 2005; White, 2005). In medicine, it became incorporated into the curriculum in nearly all medical schools in the U.S. and Europe (Frankel, Quill, \& McDaniel, 2003) and was integrated into the accreditation requirements for medical residencies in the U.S. (Frankel \& Quill, 2005). It also figures prominently in recent Institute of Medicine reports (e.g., 2001, 2004) which have emphasized that it will be difficult to improve medical outcomes for Americans without giving much more attention to behavioral factors. There is also widespread consensus across the mental health specializations regarding the importance of integrating biological and sociocultural along with psychological factors into client case conceptualizations (e.g., Kaslow et al., 2007; Melchert, 2007). Virtually any of our standard textbooks for learning mental health assessment, along with practice guidelines, accreditation and licensure standards, and standards of practice identified by disciplinary bodies and malpractice courts emphasize that biological and sociocultural considerations need to be incorporated into mental health assessment and case conceptualization. Indeed, there

[Citation: Journal/Monograph Title, Vol. XX, No. X (yyyy): pg. XX-XX. DOI. This article is @ [Publisher's Name] and permission has been granted for this version to appear in e-Publications@Marquette. [Publisher] does not grant permission for this article to be further copied/distributed or hosted elsewhere without the express permission from [Publisher].] 
appears to be consensus that failing to take a comprehensive approach such as this can result in incomplete assessments that can be ineffective and potentially harmful (e.g., see American Psychological Association, 2002, Ethics Code 2.01(b); Joint Commission for the Accreditation of Health care Organizations, 2006a; Kaslow et al., 2007).

Despite the widespread use and acceptance of a BPS framework in the mental health field, there has been very little examination of its use in actual clinical practice. The field of medicine has examined these issues at some length (Frankel et al., 2003; White, 2005), but there has been little investigation of the extent to which mental health assessment and case conceptualization conform to a BPS approach. In fact, only one study was found that examined this question, and this study investigated the use of a BPS perspective by psychiatry residents. In this study, McClain, O'Sullivan, and Clardy (2004) investigated whether psychiatric residents formulated integrative case conceptualizations according to a BPS framework. Two board-certified psychiatrists independently rated 79 written case conceptualizations that were submitted by residents from across all four years of training and from four different institutions. The study found that, on average, none of the groups of residents (i.e., first through fourth year of residency) wrote BPS case formulations that reached what was identified as the basic level of clinical competency. The reports typically included information regarding a wide range of biological, psychological, and sociocultural factors, but the information was not well integrated and was judged to have the potential to lead to less effective treatment. This study only examined the written case conceptualizations that were prepared specifically for purposes of the study-it did not examine documentation that was included in the clients' actual clinical files.

As a result of the lack of research investigating the comprehensiveness of therapists' actual assessment practices, very little is known about the range and specificity of assessment information that therapists obtain during their intakes and how thoroughly this information is integrated into their case conceptualizations. Given the central importance of assessment in mental health care and its impact on the treatment process, it is important to understand more about the assessment approaches permission has been granted for this version to appear in e-Publications@Marquette. [Publisher] does not grant permission for this article to be further copied/distributed or hosted elsewhere without the express permission from [Publisher].] 
currently being used by therapists in clinical practice. The strengths and weaknesses identified in current practices could be helpful for informing educational curricula as well as clinical practice.

To investigate these questions in the present study, client files from three outpatient mental health clinics were reviewed to identify the range of intake information that was assessed, the specificity and thoroughness of the information, and the extent to which the information was integrated into the assessment findings. The study also examined whether therapists documented strengths and deficits associated with each of the BPS components to help evaluate how thoroughly the assessments were conducted (e.g., while it is important to know if a client is married or has children, it is important to also assess the impact and quality of those relationships). These data were then used to address the following study questions. What specific components of the biological, psychological, and sociocultural domains are included in psychotherapists' intake assessments? How are each of the components addressed in terms of level of detail, strengths, deficits, and thoroughness? How thoroughly is the assessment information integrated into client case conceptualization? Do various client characteristics (e.g., type of Axis I diagnosis, having an Axis II or III diagnosis or a low Axis V score) affect the level of detail and comprehensiveness of the assessment information in client files? And is the use of more detailed and comprehensive intake forms associated with therapists obtaining more thorough intake information? This appears to be the first study to empirically investigate these questions, and consequently an instrument also needed to be developed to measure the level of detail, thoroughness, and integration with which intake assessments are documented in client files.

\section{Methods}

\section{Client Files}

A total of 163 client case files from three mental health clinics located in a metropolitan area of Wisconsin were examined in this study. The first clinic was a comprehensive community-based mental health agency offering a wide range of services primarily to individuals without medical insurance. Clinic 2 was also a community-based 
counseling center offering a wide range of services to a broad range of primarily insured clients. Clinic 3 was a substance abuse treatment clinic which serves primarily uninsured and homeless men. Two of the three clinics were directed by a licensed psychologist, and the third was managed by a team which included licensed masters- and doctoral-level therapists. All three agencies were approved as certified mental health clinics by the State of Wisconsin Department of Health Services, making them eligible for reimbursement through insurance companies and government health care programs. There were 51 files reviewed from Clinic 1 , including those from 30 female clients $(58.8 \%)$. Their mean age was 41.59 years $(S D=12.05$, range $=24-$ $65)$. Fifty files were examined from Clinic 2, including $22(66.0 \%)$ for female clients; the mean age for these clients was $37.56(S D=11.32$, range $=19-57)$. All of the files from Clinic 3 involved male clients $(n=$ 62 ) and their mean age was $44.79(S D=9.08$, range $=23-59)$.

All of the reports and notes from the client files were examined, including any intake summary or report, test protocol form, progress note, or any other form of notes containing information obtained during the first four sessions a client was seen. If reports from referral or other sources had provided assessment information before the fourth session, those reports were also included in the data collection. Though the intake assessments examined in this study were generally completed in one or two sessions, an extended intake period was used to minimize the possibility that intake information would be missed and the study would underestimate the amount of information collected through the intake procedures at these clinics.

The client files that were examined included consecutive admissions for each therapist who participated in this study. For each therapist, the files for his or her last 20 clients were examined and included in the data collection if (1) the client was at least 18 years of age; (2) the client had been seen for at least 4 sessions; and (3) the client participated in individual therapy. Family, couple, and group therapy cases were excluded because intake procedures are sometimes less extensive for these treatment formats. All of the files that were examined were written before the therapists agreed to participate. Therefore, the files represent actual clinical practice or treatment-as-usual, and not documentation that had been prepared 
with the knowledge that it was going to be reviewed and evaluated by a researcher.

The 163 clients whose files were examined were served by 14 different therapists, 3 from Clinic 1, 4 from Clinic 2, and 7 from Clinic 3. Seven of the 14 therapists were students pursuing master's degrees in counseling, completing their internships, and all of these were receiving weekly individual supervision by a licensed clinical social worker or a licensed psychologist. Of the rest, two had completed a master's degree in counseling and a third had completed a doctoral degree in counseling psychology. Of these 10 unlicensed therapists, three were supervised by a licensed master's-level practitioner and seven were supervised by a licensed psychologist. Three of the remaining four therapists were licensed clinical social workers (one of these also had a PhD. in social welfare) and the fourth was a licensed marriage and family therapist. These 14 clinicians had a wide range of experience in the field ranging from 1 to 29 years $(M=6.92, S D=$ 8.72).

\section{Procedure}

In addition to the primary researcher's review of all 163 study files, a second research assistant rated a subset of the files to examine interrater reliability. After learning and practicing the instrument that was used to rate the client files, the two raters independently (i.e., blindly) rated five files to establish initial interrater reliability (following the recommendations of Babbie, 2004). All disagreements in ratings were reviewed, and retraining and adjustments were made as needed until all ratings were within one point of each other, the a priori criterion that was established to indicate an acceptable level of reliability for this study. After the initial reliability training was completed, the research assistant independently rerated two of the files from each 10 files that were reviewed in order to continually monitor the level of interrater reliability over the entire course of data collection (i.e., to monitor rater drift). As a result, $37(22.7 \%)$ of the 163 client files were rated independently by two researchers.

\section{Instrument}

[Citation: Journal/Monograph Title, Vol. XX, No. X (yyyy): pg. XX-XX. DOI. This article is @ [Publisher's Name] and permission has been granted for this version to appear in e-Publications@ Marquette. [Publisher] does not grant permission for this article to be further copied/distributed or hosted elsewhere without the express permission from [Publisher].] 
Biopsychosocial Framework Comprehensiveness Form: An assessment instrument was developed for this study to rate the level of detail and thoroughness of the intake information that was documented in clients' case files. Five prominent systems which utilize a BPS approach were reviewed in order to identify the specific biological, psychological, and sociocultural components that are commonly included in comprehensive mental health intake assessments. These five systems included the Provision of Care Standards used by the Joint Commission for the Accreditation of Health care Organizations (JCAHO, 2006a) to evaluate the adequacy of the intake process used by inpatient or outpatient behavioral health care facilities accredited by JCAHO. JCAHO (2006b) also provides a more detailed Self-Assessment system that can be used by health care facilities to help insure that they are compliant with the Provision of Care standards. The Addiction Severity Index (McLellan, Carise, Coyne, \& Jackson, 1999) is a widely used comprehensive assessment system in the addictions field that utilizes a semistructured clinical interview format to systematically obtain BPS data from clients. Sperry $(1988,1999,2006)$ developed Biopsychosocial Therapy to take a comprehensive integrative BPS approach to mental health care. Finally, the American Psychiatric Association in 2006 published a new edition of the Practice Guidelines for the Treatment of Psychiatric Disorders, which includes guidelines for conducting general psychiatric evaluations (American Psychiatric Association, 2006).

After the specific BPS components included in these five systems were tabulated, a master list of 25 components was developed that captured all the components included in these five systems (these are listed in Table 3 below). Any additional information found in clients' files that was not captured by these 25 components was to be noted separately so that all areas of clients' lives that were documented in the study files were included in the data analysis. Frequency of BPS Components Assessed by Site

To use the BPS Framework Comprehensiveness Form, the researcher first reviewed all of the documentation found in a client file relating to the first four counseling sessions and noted which of the 25 BPS components had been addressed. Notations were then made regarding any strengths associated with each component (e.g., aspects that were described as being helpful or a benefit to the client)

[Citation: Journal/Monograph Title, Vol. XX, No. X (yyyy): pg. XX-XX. DOI. This article is @ [Publisher's Name] and permission has been granted for this version to appear in e-Publications@Marquette. [Publisher] does not grant permission for this article to be further copied/distributed or hosted elsewhere without the express permission from [Publisher].] 
and any deficits associated with each component (e.g., aspects that were described as being a hindrance, difficult, or harmful). After these notations were completed, the researcher then made ratings using the two scales that were included in the instrument. The first scale, the Detail and Comprehensiveness Scale, was used to rate the level of detail and thoroughness of the documentation found for each of the 25 individual components. The scale ranges from zero to four with a score of zero assigned if the component was not addressed at all. If only a few details regarding the component were mentioned or only a checkmark was placed in a box indicating the component had been assessed (e.g., a checkmark indicating that a client was married but no further information was documented), a score of one was assigned. A score of two was assigned if most or nearly all of the basic information regarding a component was addressed. To obtain a score of three, most or nearly all of the relevant details needed to be documented, and the component was addressed either in terms of strengths or in terms of deficits. A score of four was assigned if most or nearly all details regarding a component were present, deficits were addressed, and strengths were also addressed. Examples for each of these ratings for the substance abuse component are provided in Table 1.

After rating the 25 individual components, the raters also gave a global score for each file using the Overall Use of a BPS Approach Scale. The rubric for this scale was adapted from McClain et al.'s (2004)Psychiatric Residents' Case Formulation Scoring Rubric. Scores on this scale range from zero to four and are based on a global evaluation of the use of a comprehensive, integrative BPS approach to assessment as reflected by all of the file documentation for a client's first four sessions. A zero indicates that assessment information is missing regarding critical biological, psychological, and/or sociocultural components within the context of a particular case, while a four indicates that a client's strengths and weaknesses are addressed comprehensively across the BPS domains and with attention given to individual and sociocultural differences. At this level, information is integrated so that strengths are reinforced and amplified, and weaknesses and problems are addressed. Issues are prioritized to reflect the client's circumstances and preferences and to maximize treatment effectiveness. The rubric used to make the ratings along with an example for each rating level are found in Table 2. permission has been granted for this version to appear in e-Publications@Marquette. [Publisher] does not grant permission for this article to be further copied/distributed or hosted elsewhere without the express permission from [Publisher].] 
NOT THE PUBLISHED VERSION; this is the author's final, peer-reviewed manuscript. The published version may be accessed by following the link in the citation at the bottom of the page.

\section{Reliability of the Ratings}

The 37 client files that were examined by two raters were first evaluated on the basis of the 25 individual BPS components that were included in the Detail and Comprehensiveness Scale. There were 12 disagreements out of the 925 ratings made across these 37 files (i.e., 25 components for each of the 37 files). There were also eight disagreements out of the 37 global ratings made using the Overall Use of a BPS Approach Scale. There was no rating discrepancy greater than one point for either of these scales. Consequently, agreement within one point on the ratings was $100 \%$, while identical ratings were made for $97.8 \%$ of the individual components and for $78.4 \%$ of the global scores. The kappa coefficient for the interrater reliability of the ratings of the individual components was .97, and was .57 for the global ratings. Cicchetti (1994) considers kappa coefficients from .40 to .59 to be fair, .60 to .75 as good, and above .75 as excellent. In each case where there was a disagreement, the two raters re-reviewed the file, discussed the evidence, and reached a consensus rating to resolve the disagreement.

\section{Client Diagnostic Characteristics}

A large number of specific DSM-IV-TR (American Psychiatric Association, 2000) diagnoses were found in the client files. To allow for a meaningful statistical analysis of the data, these diagnoses were collapsed into the general categories used in the DSM-IV-TR. After this was done, the most common primary Axis I diagnosis was a mood disorder $(44.8 \%)$, followed by a substance abuse disorder $(19.0 \%)$ or anxiety disorder (12.3\%). Secondary diagnoses on Axis I were found in $73.0 \%$ of the files, the most common being an anxiety disorder $(25.2 \%)$, mood disorder $(21.5 \%)$, or substance related disorder (14.7\%). Three or more diagnoses on Axis I were present in $26.4 \%$ of the files. No diagnosis was given on Axis II in $58.3 \%$ of the cases and deferred diagnosis was made in $33.1 \%$ of the cases. Antisocial Personality Disorder was the most common Axis II diagnosis given $(4.9 \%)$ followed by Borderline $(1.2 \%)$ and Personality Disorder Not Otherwise Specified (1.2\%).

A majority of the files included no diagnosis on Axis III (General Medical Conditions and Diagnoses). This was in part due to an

[Citation: Journal/Monograph Title, Vol. XX, No. X (yyyy): pg. XX-XX. DOI. This article is @ [Publisher's Name] and permission has been granted for this version to appear in e-Publications@ Marquette. [Publisher] does not grant permission for this article to be further copied/distributed or hosted elsewhere without the express permission from [Publisher].] 
administrative decision that had recently been made at Clinic 3 (the substance abuse treatment clinic) to record only Axis I and II diagnoses. Hypertension was the most commonly reported medical condition ( $n=10)$, followed by musculoskeletal problems $(n=9)$ and back pain $(n=6)$. A variety of primary psychosocial stressors were reported on Axis IV, while 81 of the files included no entry on this Axis (and no stressors were reported at Clinic 3). By far the most commonly reported psychosocial stressor was primary support group problems $(n=46)$ followed by legal system problems $(n=9)$ and economic problems $(n=8)$. Axis $V$ Global Assessment of Functioning (GAF) scores were present in all of the files for Clinics 1 and 2 (none were reported at Clinic 3$)$. The mean GAF score was $56.39(S D=9.15$, range $=38$ to 90 ).

\section{Detail and Comprehensiveness}

After reviewing the file documentation, notations were made regarding whether information was present regarding each of the 25 individual BPS components and whether strengths and weaknesses regarding each component had been assessed. Out of the 25 BPS components that could be documented in each file, the smallest number of components documented was 15 and the largest was 24 ( $M$ $=19.28, S D=2.61)$. There were no client data found in any of the 163 files that was not included in these 25 categories-in other words, these 25 components represent an exhaustive categorization of all the intake information that was found across the study files, a finding that supports the content related validity of the instrument as well. Six components were documented in all cases (i.e., Individual Psychiatric History, History of Present Illness, Suicidal Ideation, Relationships, Employment, and Legal Issues), whereas Childhood Health History was documented in only six files (3.7\%; see Table 3 ). There was substantial consistency in the frequency with which most of the components were assessed across the clinics, but there were several components that were inconsistently assessed across the clinics and/or across the individual therapists at those clinics (i.e., the last five components in the psychological domain and the last four components in the sociocultural domain in Table 3 ).

Deficits were most often documented in terms of Substance Use History (42.9\%) and Relationships (36.2\%). All of the files at Clinic 3 
assessed deficits associated with clients' substance use history, though only $7.9 \%$ of the files included documentation of deficits with regard to substance use at the other two clinics. After Substance Use History and Relationships, only one other component (i.e., Family History, $10.4 \%$ ) had deficits documented in more than $10 \%$ of the files. No deficits were documented in any file for seven of the 25 BPS components (i.e., Childhood Health History, Suicidal Ideation, Behavioral Observations, Education History, Involvement in Activities of Personal Interest or Hobbies, Multicultural Issues, and Spirituality).

Strengths were also infrequently documented, though they were documented more frequently than deficits. Strengths were most frequently documented for Personality Styles and Characteristics (33.7\% of the files). There were also eight other components where strengths were noted in at least $20 \%$ of the files (i.e., General Medical History, Current Living Situation, Family History, Relationships, Employment, Financial Resources, Educational History, and Interests/Hobbies). For all of the rest of the components, however, strengths were documented in less than $5 \%$ of the study files.

After the above notations were completed, a rating was made using the Detail and Comprehensiveness Scale for each of the 25 individual BPS components. Across all 25 components and all 163 client files, $22.9 \%$ of the ratings were a 0 indicating that no information was found, $32.3 \%$ were a $1,36.4 \%$ were a $2,6.5 \%$ were a 3 , and only $1.9 \%$ were a 4 rating. Only one BPS component (i.e., Relationships) received a mean score above two at each of the clinics (see Table 4). In contrast, several components received mean scores near zero. At Clinic 3 (the substance abuse clinic), there was substantial consistency in the level of detail and comprehensiveness with which the components were documented, reflecting the use of a standardized intake assessment instrument at this site (i.e., the Addiction Severity Index). There also was a very weak correlation between the mean rating for each file and the number of years of clinical experience of the therapist who wrote the file, $r=.16, p=.04$ (effect size $r^{2}=.026$ or very small). 
NOT THE PUBLISHED VERSION; this is the author's final, peer-reviewed manuscript. The published version may be accessed by following the link in the citation at the bottom of the page.

\section{Overall Use of a Biopsychosocial Approach}

A single global score was assigned to each file using the Overall Use of a BPS Approach Scale. No file received a score of 0 , but the large majority of files $(85.9 \%)$ were coded as a level one, indicating a general lack of focus and integration (see Table 5). In addition, 18 files $(11.0 \%)$ were rated a two, the midpoint on the scale intended to indicate "basic competency." Only five files (3.1\%) were rated a 3 for showing a higher level of integration of BPS components into the assessment, and no file received a 4 reflecting comprehensive BPS assessment and prioritization of needs. The mean score obtained across all 163 client files was $1.17(S D=.45)$. While there was a statistically significant difference in scores between sites, $F(2,160)=$ $10.25, p<.001$, the potential impact of the two therapists at Clinic 1 who accounted for all of the " 3 " ratings in the dataset renders the significance of this finding inconclusive. There was a very weak correlation between scores on this scale and the years of experience of the therapist who wrote the file, $r=.16, p=.05$ (effect size $r^{2}=.026$ or very small).

\section{Client Characteristics}

To examine whether particular client diagnostic categories were associated with higher Detail and Comprehensiveness scores, a oneway analysis of variance (ANOVA) was computed across the primary Axis I diagnostic categories. Mean scores for the various diagnostic categories were quite similar (ranging from 1.26 to 1.34 ) and the ANOVA result was not statistically significant, $F(5,157)=1.27, p$ $=.28$. A second one-way ANOVA was computed using the Overall Use of a BPS Approach Scale scores and the result also was not significant, $F(5,157)=1.37, p=.24$. These results suggest that Axis I diagnostic category did not affect the level of comprehensiveness or integration of assessment information that was documented in the study files.

The presence of a diagnosis on Axis II, however, was associated with a higher mean Detail and Comprehensiveness score across all the 25 BPS components. The mean score was $1.38(S D=.17)$ for files where an Axis II diagnosis was present versus $1.28(S D=.12)$ for files where no diagnosis was made, $F(1,161)=17.91, p<.001$. Scores on the Overall Use of a BPS Approach Scale, however, were not permission has been granted for this version to appear in e-Publications@Marquette. [Publisher] does not grant permission for this article to be further copied/distributed or hosted elsewhere without the express permission from [Publisher].] 
statistically significantly different between those with and without an Axis II diagnosis, $F(1,161)=1.68, p=.20$.

The presence of a diagnosis on Axis III was not associated with a higher mean Detail and Comprehensiveness score for all the 25 BPS components, $F(1,99)=1.82, p=.18$. Likewise, scores on the Overall Use of a BPS Approach Scale were not statistically significantly different between those with and without an Axis III diagnosis, $F(1$, $99)=0.24, p=.63$. The presence of psychosocial stressors on Axis IV also was not associated with a higher mean Detail and Comprehensiveness score for all the 25 BPS components, $F(1,99)=$ $3.98, p=.05$. Scores on the Overall Use of a BPS Approach Scale were not statistically significantly different between those with and without Axis IV stressors, $F(1,99)=2.07, p=.15$.

To address whether Axis V Global Assessment of Functioning (GAF) scores were associated with comprehensiveness and detail in the therapists' BPS intake assessments, correlation coefficients were computed between GAF scores and the mean Detail and Comprehensiveness scores. Neither the correlation coefficient between the GAF scores and the mean Detail and Comprehensiveness scores ( $r$ $=.15, p=.14$ ) or between the GAF scores and the Overall Use of a BPS Approach scores $(r=.08, p=.42)$ was statistically significant.

Gender of the client also was not associated with mean Detail and Comprehensiveness scores for the 25 BPS components, $F(1,161)$ $=.85, p=.36$. Client gender was statistically significantly associated with Overall Use of a BPS Approach Scale scores, however, $F(1,161)$ $=6.60, p=.01$ (female client files $M=1.30, S D=.61$; male clients files $M=1.09, S D=.29$ ). Because Clinic 3 only included males, this result was reanalyzed using only participants from Clinics 1 and 2, and that result was not statistically significant, $F(1,99)=3.37, p=.07$.

\section{Comprehensiveness of Intake Forms}

To investigate the possibility that more detailed and comprehensive intake forms resulted in therapists obtaining more comprehensive assessment information, the number of individual BPS components included on the three clinic intake forms was compared to the number of BPS components that had been documented in the 
client files at those clinics (as reported in Table 3). The mean number of BPS components noted in the intake documentation at Clinic 1 was $20.06(S D=1.43)$, more than the 16 components included on their intake form. The mean number of BPS components noted at Clinic 2 was $22.10(S D=.54)$, which is greater than the 20 components included on this clinic's intake form. The mean number of BPS components noted in the intake documentation at Clinic 3 was 16.35 $(S D=.68)$, which is very close to the 16 BPS components included on that clinic's intake form. Though only three clinics were examined, these findings suggest the possibility that therapists document information regarding larger numbers of BPS components when their clinics use intake forms that include a larger number of BPS components.

\section{Discussion}

This appears to be the first study to examine the comprehensiveness and integration of the intake documentation found in outpatient mental health files. This examination found that the participating therapists were clearly collecting client intake information from across all of the three general BPS domains. In fact, the study files included intake information regarding roughly one half of the 25 specific BPS components in nearly every case (in at least $98 \%$ of the files for 12 of the 25 components). Despite significant differences in the populations served by the three participating clinics, there was significant consistency across the clinics and across the therapists within clinics regarding the type of intake information that was documented in the client files.

It was also clear, however, that the documented intake information tended not to be detailed or comprehensive. Strengths or weaknesses associated with the various components were infrequently documented, and the Relationships component was the only one which received an average Detail and Comprehensiveness Scale score greater than 2.0 at all three clinics. The study also found generally low ratings on the Overall Use of a BPS Approach Scale. In the large majority of the files $(85.9 \%)$, the overall thoroughness and integration of the assessment information was rated 1 (on the 0 -to- 4 scale), which was defined as lower than the level indicating basic clinical 
competency. Therapists with more clinical experience tended to receive slightly higher ratings than those with less experience.

The level of thoroughness and integration of the intake documentation made by the therapists in this study was quite similar to that found by McClain et al. (2004). They used a somewhat different 0-to- 6 rating scale, but found that all of the groups of first- through fourth-year psychiatry residents in their study wrote case reports that received average ratings lower than the level of "Competent formulation for successful treatment of standard cases. Some evidence of integration" (p. 90). These appear to be the only two studies that have examined this question to date. While replication of this research is needed, these initial results suggest that therapists from a variety of specializations do collect assessment information from across the BPS domains, though they tend not to collect comprehensive or detailed information nor integrate the information they collect in a BPS manner that is designed to maximize treatment effectiveness.

There was very tentative evidence that the use of more detailed blank intake forms was associated with more comprehensive BPS intake information being collected by therapists. This would not be an unexpected finding, but it does raise questions that could be relatively easily examined in future research. It is possible that simply changing the length or detail of intake forms, or adding prompts to inquire about strengths and weaknesses, could increase the comprehensiveness of information collected in mental health intake assessments.

The methodological limitations of this study must also be considered when interpreting the present findings. First, the representativeness of the present findings is unknown, though it is remarkable how similar these findings are to those of McClain et al. (2004) even though the therapists in these two studies were from quite different mental health specializations. In addition, only written case documentation was examined and evaluated in this study. No attempt was made to examine the thoroughness of this documentation by comparing it to recordings of the actual client sessions. It is certainly possible that the therapists were significantly more thorough and detailed in their in-session conversations with clients than what is reflected in the case documentation. If this did occur, however, it was not being documented in clients' files, which is a problem in itself. 
State and federal laws, accreditation and institutional policies, and ethics codes require that case documentation be maintained regarding all services offered. Nonetheless, it is not possible to infer how well the documentation that was examined in this study reflects the intake information that was actually discussed in-session.

The instrument developed for the present study may be useful in future research as well as for training and supervision in mental health assessment. The interrater reliability findings for the two scales in the instrument ranged from fair to excellent. In terms of the content-related validity of the instrument, this study also found that all of the information contained in a sample of 163 outpatient files could be categorized into the 25 components included in the BPS Framework Comprehensiveness Form, and all of the components were relevant in at least some of the cases. The study therapists may have discussed additional issues in-session that were not documented in their case notes, and there may be other categories of information that are relevant for other client groups (e.g., inpatients, institutionalized clients). Nonetheless, the study findings provide empirical support for the usefulness of these 25 categories for evaluating the information documented in outpatient mental health intake assessments.

Engel (1977) and many others since then have concluded that a comprehensive, integrative BPS approach is necessary for understanding medical and mental health and functioning. The importance of a BPS assessment approach for informing psychological treatment has not received extensive empirical examination, however. More studies like the one above are needed to learn how psychological assessments are conducted by therapists across specializations and working in different treatment settings and with different client populations. These data could then be used to address several critically important questions. Do more comprehensive and integrative BPS assessments affect clients' perceptions of the working alliance and relationship? Do they affect treatment planning and intervention? What is their relationship to treatment outcomes? These questions have not been investigated empirically to date. This research should be a high priority given the possibility that the effectiveness of behavioral health care might be improved if intake assessments are conducted in a more thorough and integrative manner. If a comprehensive, integrative BPS approach to assessment and case conceptualization is found to lead to

[Citation: Journal/Monograph Title, Vol. XX, No. X (yyyy): pg. XX-XX. DOI. This article is @ [Publisher's Name] and permission has been granted for this version to appear in e-Publications@Marquette. [Publisher] does not grant permission for this article to be further copied/distributed or hosted elsewhere without the express permission from [Publisher].] 
NOT THE PUBLISHED VERSION; this is the author's final, peer-reviewed manuscript. The published version may be accessed by following the link in the citation at the bottom of the page.

improved treatment outcomes, it would have very important implications for education, training, and practice in the behavioral health care field.

Corresponding Author: Timothy Melchert, Department of Counselor Education and Counseling Psychology, 168F Schroeder Complex, 561 N. 15th St., Marquette University, Milwaukee, WI 53217; 414-288-7379

\section{References}

American Psychiatric Association. (2000). Diagnostic and statistical manual of mental disorders (4th ed., text revision). Washington, DC: Author.

American Psychiatric Association. (2006). Practice guidelines for the treatment of psychiatric disorders: Compendium 2006. Arlington, VA: American Psychiatric Association.

American Psychological Association. (2002). Ethical principles of psychologist and code of conduct. American Psychologist, 57, 1060-1075.

Anchin, J. C. (2008). Pursuing a unifying paradigm for psychotherapy: Tasks, dialectical considerations, and biopsychosocial systems metatheory. Journal of Psychotherapy Integration, 18, 310-349.

Babbie, E. (2004). The practice of social research (10th ed.). Belmont, CA: Wadsworth/Thomson Learning.

Cicchetti, D. V. (1994). Guidelines, criteria, and rules of thumb for evaluating normed and standardized assessment instruments in psychology. Psychological Assessment, 6, 284-290.

Engel, G. L. (1977). The need for a new medical model: A challenge for biomedicine. Science, 196, 129-136.

Frankel, R. M., \& Quill, T. (2005). Integrating biopsychosocial and relationship-centered care into mainstream medical practice: $\mathrm{A}$ challenge that continues to produce positive results. Families, Systems, \& Health, 23, 413-421.

[Citation: Journal/Monograph Title, Vol. XX, No. X (yyyy): pg. XX-XX. DOI. This article is @ [Publisher's Name] and permission has been granted for this version to appear in e-Publications@ Marquette. [Publisher] does not grant permission for this article to be further copied/distributed or hosted elsewhere without the express permission from [Publisher].] 
NOT THE PUBLISHED VERSION; this is the author's final, peer-reviewed manuscript. The published version may be accessed by following the link in the citation at the bottom of the page.

Frankel, R. M., Quill, T. E., \& McDaniel, S. H. (Eds.). (2003). The biopsychosocial approach: Past, present, and future. Rochester, NY: University of Rochester Press.

Guastello, S. J., Koopmans, M., \& Pincus, D. (Eds.). (2009). Chaos and complexity in psychology: The theory of nonlinear dynamical systems. New York: Cambridge University Press.

Institute of Medicine. (2001). Health and behavior: The interplay of biological, behavioral, and societal influences. Washington, DC: National Academies Press.

Institute of Medicine. (2004). Improving medical education: Enhancing the behavioral and social science content of medical school curricula. Washington, DC: Author.

Joint Commission on Accreditation of Healthcare Organizations. (2006a). Comprehensive accreditation manual for behavioral health care: 2006, Standards, rationales, elements of performance, scoring. Oakbrook Terrace, IL: Joint Commission Resources.

Joint Commission on Accreditation of Healthcare Organizations. (2006b). Joint Commission on Accreditation of Healthcare Organizations: Behavioral healthcare self-assessment. Retrieved from www.JCAHO.org

Kaslow, N. J., Bollini, A. M., Druss, B., Glueckauf, R. L.Goldfrank, L. R.Kelleher, K. J., . . .Zeltzer, L. (2007). Health care for the whole person: Research update. Professional Psychology: Research and Practice, 38, 278-289.

Magnavita, J. J. (2008). Toward unification of clinical science: The next wave in the evolution of psychotherapy? Journal of Psychotherapy Integration, 18, 264-291.

McClain, T., O'Sullivan, P. S., \& Clardy, J. A. (2004). Biopsychosocial formulation: Recognizing educational shortcomings. Academic Psychiatry, 28, 88-94.

McLellan, A. T., Carise, D., Coyne, T. H., \& Jackson, T. R. (1999). Addiction severity index (5th ed.). Philadelphia: Treatment Research Institute.

[Citation: Journal/Monograph Title, Vol. XX, No. X (yyyy): pg. XX-XX. DOI. This article is @ [Publisher's Name] and permission has been granted for this version to appear in e-Publications@Marquette. [Publisher] does not grant permission for this article to be further copied/distributed or hosted elsewhere without the express permission from [Publisher].] 
NOT THE PUBLISHED VERSION; this is the author's final, peer-reviewed manuscript. The published version may be accessed by following the link in the citation at the bottom of the page.

Melchert, T. P. (2007). Strengthening the scientific foundations of professional psychology: Time for the next steps. Professional Psychology: Research and Practice, 38, 34-43.

Meyer, A. (1917). Progress in teaching psychiatry. Journal of the American Medical Association, 69, 861-863.

Norcross, J. C. (2005). A primer on psychotherapy integration. In J. C.Norcross \& M. R.Goldfried (Eds.), Handbook of psychotherapy integration, 2nd ed. (pp. 3-23). New York: Oxford University Press.

Sperry, L. (1988). Biopsychosocial therapy: An integrative approach for tailoring treatment. Individual Psychology, 44, 225-235.

Sperry, L. (1999). Biopsychosocial therapy. The Journal of Individual Psychology, 55, 233-247.

Sperry, L. (2006). Psychological treatment of chronic illness: The biopsychosocial therapy approach. Washington, DC: American Psychological Association.

Suchman, A. L. (2005). The current state of the biopsychosocial approach. Families, Systems, and Health, 23, 450-452.

Von Bertalanffy, L. (1950). An outline of general system theory. The British Journal for the Philosophy of Science, 1, 134-165.

Von Bertalanffy, L. (1968). General system theory: Foundations, development, applications. New York: George Braziller.

White, P. (2005). Biopsychosocial medicine: An integrated approach to understanding illness. New York: Oxford University Press.

[Citation: Journal/Monograph Title, Vol. XX, No. X (yyyy): pg. XX-XX. DOI. This article is ( [Publisher's Name] and permission has been granted for this version to appear in e-Publications@Marquette. [Publisher] does not grant permission for this article to be further copied/distributed or hosted elsewhere without the express permission from [Publisher].] 
NOT THE PUBLISHED VERSION; this is the author's final, peer-reviewed manuscript. The published version may be accessed by following the link in the citation at the bottom of the page.

\section{Table 1}

Examples for Scores on the Detailed and Comprehensiveness Scale for the Substance Use Component

\begin{tabular}{|c|c|c|}
\hline Seore & Rating Description & Example \\
\hline 0 & $\begin{array}{l}\text { No information documented } \\
\text { regarding the component. }\end{array}$ & $\begin{array}{l}\text { [No information was found regarding the use of } \\
\text { psychoactive substances.] }\end{array}$ \\
\hline 1 & $\begin{array}{l}\text { Only a few details or basic } \\
\text { data are mentioned; or a } \\
\text { checkbox for this component } \\
\text { is marked but no further } \\
\text { information is provided. }\end{array}$ & "Client states she drinks alcohol." \\
\hline 2 & $\begin{array}{l}\text { Most or nearly all basic details } \\
\text { or data are present: strengths } \\
\text { and/or weaknesses may be } \\
\text { mentioned minimally, but not } \\
\text { clearly assessed as a strength } \\
\text { or a deficit. }\end{array}$ & $\begin{array}{l}\text { "Client reports drinking alcohol socially, } \\
\text { approximately twice per month. She reports not } \\
\text { smoking and does not consume caffeine or any } \\
\text { illicit drugs." }\end{array}$ \\
\hline 3 & $\begin{array}{l}\text { Most or nearly all details or } \\
\text { data are present plus one of } \\
\text { the following two is also met: } \\
\text { (1) strengths associated with } \\
\text { the component are described, } \\
\text { or (2) deficits associated with } \\
\text { the component are described. }\end{array}$ & $\begin{array}{l}\text { "Client reports drinking alcohol socially, } \\
\text { approximately twice per month. She reports not } \\
\text { smoking and does not consume caffeine or any } \\
\text { illicit drugs. Client reports drinking has negative } \\
\text { impact because when she goes out and drinks with } \\
\text { friends, she usually drinks too much and does not } \\
\text { want to get out of bed the next day." }\end{array}$ \\
\hline 4 & $\begin{array}{l}\text { All of the following criteria } \\
\text { are met: (1) most or nearly all } \\
\text { details or data are present; (2) } \\
\text { strengths associated with the } \\
\text { component are described, and } \\
\text { (3) deficits associated with the } \\
\text { component are described. }\end{array}$ & $\begin{array}{l}\text { "Client reports drinking alcohol socially, } \\
\text { approximately twice per month. She reports not } \\
\text { smoking and does not consume caffeine or any } \\
\text { illicit drugs. She reports that drinking on a social } \\
\text { basis has been helpful because she gets to go out } \\
\text { with friends and feels more comfortable } \\
\text { socializing and meeting new people. Client reports } \\
\text { that drinking also has a negative impact because } \\
\text { when she goes out and drinks with friends, she } \\
\text { usually drinks too much and does not want to get } \\
\text { out of bed for work the next morning." }\end{array}$ \\
\hline
\end{tabular}

[Citation: Journal/Monograph Title, Vol. XX, No. X (yyyy): pg. XX-XX. DOI. This article is @ [Publisher's Name] and permission has been granted for this version to appear in e-Publications@Marquette. [Publisher] does not grant permission for this article to be further copied/distributed or hosted elsewhere without the express permission from [Publisher].] 
NOT THE PUBLISHED VERSION; this is the author's final, peer-reviewed manuscript. The published version may be accessed by following the link in the citation at the bottom of the page.

\section{Table 2}

\section{Description of File Documentation for Each Level on the Overall Use of a Biopsychosocial Approach Scale}

\begin{tabular}{|c|c|c|}
\hline Score & Rating Description & Example \\
\hline 0 & $\begin{array}{l}\text { Assessment is missing critical biological, } \\
\text { psychological, and sociocultural information } \\
\text { in the context of the particular case. }\end{array}$ & $\begin{array}{l}\text { Client presents with symptoms of } \\
\text { depression, but the clinician does not obtain } \\
\text { information related to suicidal ideation. }\end{array}$ \\
\hline 1 & $\begin{array}{l}\text { The clinician obtained information } \\
\text { regarding a variety of components across the } \\
\text { biological, psychological and sociocultural } \\
\text { domains, but a lack of focus and attention to } \\
\text { important concerns could lead to less } \\
\text { effective treatment. }\end{array}$ & $\begin{array}{l}\text { Client presents with symptoms of depression } \\
\text { and clinician does obtain some information } \\
\text { related to psychiatric history, but neglects } \\
\text { important components such as previous } \\
\text { diagnoses of mood disorders, previous } \\
\text { treatments and their outcome, and past } \\
\text { psychological traumas. }\end{array}$ \\
\hline 2 & $\begin{array}{l}\text { Basic competency. The clinician obtained } \\
\text { comprehensive biological, psychological, } \\
\text { and sociocultural information, and there is } \\
\text { evidence of integration of this information } \\
\text { to address the client's most important } \\
\text { concerns. }\end{array}$ & $\begin{array}{l}\text { Client presents with symptoms of depression } \\
\text { and the clinician obtains information related } \\
\text { to psychiatric and personal history and past } \\
\text { traumas; climician shows link between } \\
\text { current symptoms and this history. }\end{array}$ \\
\hline 3 & $\begin{array}{l}\text { The clinician obtained comprehensive } \\
\text { biological, psychological, and sociocultural } \\
\text { information, as well as information about } \\
\text { some of the strengths and weaknesses the } \\
\text { client possesses. The integration of this } \\
\text { information helps to prioritize the client's } \\
\text { concerns and problems. }\end{array}$ & $\begin{array}{l}\text { Client presents with symptoms of depression } \\
\text { and the clinician obtains information related } \\
\text { to psychiatric history; clinician shows link } \\
\text { between current symptoms and history; } \\
\text { clinician obtains information from the client } \\
\text { to help understand detrimental and } \\
\text { beneficial patterns of responses to the life } \\
\text { events. }\end{array}$ \\
\hline 4 & $\begin{array}{l}\text { The clinician addressed the client's strengths } \\
\text { and weaknesses comprehensively across the } \\
\text { BPS domains, with attention given to } \\
\text { individual and sociocultural differences. } \\
\text { This information is integrated so that } \\
\text { strengths will be reinforced and amplified } \\
\text { and weaknesses and problems will be } \\
\text { addressed. Issues are prioritized to reflect } \\
\text { the client's needs, circumstances, and } \\
\text { preferences, and to maximize treatment } \\
\text { effectiveness. }\end{array}$ & $\begin{array}{l}\text { Client presents with symptoms of depression } \\
\text { and clinician obtains information related to } \\
\text { psychiatric history; clinician shows link } \\
\text { between current symptoms and history; } \\
\text { clinician obtains information about how } \\
\text { various factors are detrimental to the client's } \\
\text { functioning, and how other factors have } \\
\text { been helpful to the functioning of the } \\
\text { individual. Clinician makes a clear link } \\
\text { between various psychological factors and } \\
\text { current level of functioning, and takes into } \\
\text { account a variety of client concerns and } \\
\text { personal preferences for treatment in order } \\
\text { to maximize treatment effectiveness. }\end{array}$ \\
\hline
\end{tabular}

[Citation: Journal/Monograph Title, Vol. XX, No. X (yyyy): pg. XX-XX. DOI. This article is @ [Publisher's Name] and permission has been granted for this version to appear in e-Publications@ Marquette. [Publisher] does not grant permission for this article to be further copied/distributed or hosted elsewhere without the express permission from [Publisher].] 
NOT THE PUBLISHED VERSION; this is the author's final, peer-reviewed manuscript. The published version may be accessed by following the link in the citation at the bottom of the page.

\section{Table 3}

Frequency of BPS Components Assessed by Site

\begin{tabular}{|c|c|c|c|c|c|c|c|c|c|}
\hline \multirow[b]{2}{*}{ Domaatns } & \multirow[b]{2}{*}{ Centposents } & \multicolumn{2}{|c|}{ Clineic 1} & \multicolumn{2}{|c|}{ Clinic 2} & \multicolumn{2}{|c|}{ Clinie 3} & \multicolumn{2}{|c|}{ Total } \\
\hline & & $n$ & $\%$ & $n$ & $\%$ & " & $\%$ & " & $\%$ \\
\hline \multicolumn{10}{|c|}{ Biological } \\
\hline & Geasral.Medical Hisiany & 50 & 98.0 & 50 & 1000 & 62 & $100: 0$ & 362 & 99.4 \\
\hline & Modicatians & 49 & 96.1 & 50 & 1000 & 62 & 100.0 & 161 & 98.8 \\
\hline & Chidhood Health Histony & 4 & 78 & 1 & 20 & 1 & 16 & 6 & 3.7 \\
\hline \multicolumn{10}{|c|}{ Prychological } \\
\hline & History of Present lilimess & SI & 100.0 & 50 & 1000 & 62 & 100.0 & 163 & 1000 \\
\hline & Individual Psychiatric Histan & 51 & 100.0 & 50 & 1000 & 62 & 100.0 & 163 & 1000 \\
\hline & Saricidal Jdeation & 51 & 100.0 & 50 & 100.0 & 62 & 100.0 & 163 & 100,0 \\
\hline & Swbrtance Use Hiatory & 69 & 961 & 50 & 1000 & 62 & 100.0 & 161 & 98.8 \\
\hline & Chidhoad A buse History & 3?: & 72.5 & 50 & 1000 & 62 & 100.0 & 149 & 93.4 \\
\hline & Mental Status Examinatian (MSSE) & 51 & 1000 & 50 & 1000 & 12 & 194 & 113 & 693 \\
\hline & Psychobogical Trumar. & 50 & 980 & 50 & 1000 & 4 & 65 & 104 & 638 \\
\hline & Personalify Styles and C Charcacteristics & 41 & 80.4 & 50 & 1000 & 4 & 65 & 95 & 8.3 \\
\hline & Behavional Observations & 36 & 70.6 & 50 & 100.0 & 5 & 8.1 & 91 & 55.8 \\
\hline & Individual Dewelogmannal Hirtony & 21 & 412 & 1 & 2.0 & 0 & 00 & 22 & 13.5 \\
\hline \multicolumn{10}{|c|}{ Sociocultural } \\
\hline & Empibyment & 51 & 100.0 & 50 & 1000 & 62 & 100.0 & 163 & 100.0 \\
\hline & Legal Loshes & 51 & 1000 & 50 & 1000 & 62 & 1000 & 163 & 1000 \\
\hline & Polationshiges & 51 & 100.0 & 50 & 1000 & 62 & 1000 & 163 & 1000 \\
\hline & Cument LAing Situation'Arrabgemients & 50 & 980 & 50 & 1000 & 62 & 100.0 & 162 & 99.4 \\
\hline & Edscuation Bixtory & 30 & 980 & 50 & 100.0 & 62 & 100.0 & 162 & 994 \\
\hline & Relision & 51 & 100.0 & 49 & 98.0 & 62 & 100.0 & 162 & 99.4 \\
\hline & Family Histany & 51 & 100.0 & 50 & 1000 & 55 & 88.7 & 156 & 95.7 \\
\hline & Mulficultural Issues & 39 & 76.5 & 50 & 1000 & 62 & 1000 & 151 & 92.6 \\
\hline & Fimanciol Resownes & 13 & 255 & 50 & 1000 & 62 & 100.0 & 125 & 76,3 \\
\hline & MiNary Histon & 51 & 100.0 & 50 & 1000 & 3 & 4.8 & 104 & 63.8 \\
\hline & $\begin{array}{l}\text { Imaivemenl in Activities of Persanal } \\
\text { interest Hobbies }\end{array}$ & 1 & 20 & 46 & 92.0 & 0 & 00 & 47 & 28.8 \\
\hline & Spiribuatity & 23 & 451 & 6 & 120 & 0 & 00 & 29 & 17.8 \\
\hline
\end{tabular}

Note: Clinic $1 n=51$, Clinic $2 n=50$, Clinic $3 n=62$.

[Citation: Journal/Monograph Title, Vol. XX, No. X (yyyy): pg. XX-XX. DOI. This article is @ [Publisher's Name] and permission has been granted for this version to appear in e-Publications@Marquette. [Publisher] does not grant permission for this article to be further copied/distributed or hosted elsewhere without the express permission from [Publisher].] 
NOT THE PUBLISHED VERSION; this is the author's final, peer-reviewed manuscript. The published version may be accessed by following the link in the citation at the bottom of the page.

\section{Table 4}

Mean Scores on the Detail and Comprehensiveness Scale for Each BPS Component

\begin{tabular}{|c|c|c|c|c|c|}
\hline \multirow[b]{2}{*}{ Domains } & \multirow[b]{2}{*}{ Components } & \multirow{2}{*}{$\frac{\text { Clinic 1 }}{M(S D)}$} & \multirow{2}{*}{$\frac{\text { Clinic 2 }}{M(S D)}$} & \multirow{2}{*}{$\frac{\text { Clinic } 3}{M(S D)}$} & \multirow{2}{*}{$\frac{\text { Total }}{M(S D)}$} \\
\hline & & & & & \\
\hline \multicolumn{6}{|l|}{ Biological } \\
\hline & General Medical History & $1.82(.65)$ & $1.56(.88)$ & $2.00(00)$ & $1.81(63)$ \\
\hline & Medications & $1.69(.81)$ & $1.40(.81)$ & $2.02(13)$ & $1.72(.69)$ \\
\hline & Childhood Health History & $0.16(.54)$ & $0.02(.14)$ & $0.03(.25)$ & $0.07(.35)$ \\
\hline & Biological Overall & $1.22(.67)$ & $0.99(.61)$ & $1.35(.23)$ & $1.20(.56)$ \\
\hline \multicolumn{6}{|c|}{ Psychological } \\
\hline & Substance Use History & $1.57(.81)$ & $1.58(.76)$ & $3,00(.00)$ & $2.12(.93)$ \\
\hline & Individual Psychiatric Histony & $1.71(.61)$ & $1.46(.61)$ & $2.00(00)$ & $1.74(.53)$ \\
\hline & Histary of Present Illness & $1.92(.52)$ & $1.12(.39)$ & $2.05(22)$ & $1.72(.56)$ \\
\hline & Childhood Abuse History & $1.35(.93)$ & $1.38(.57)$ & $2.00(.00)$ & $1.61(.68)$ \\
\hline & Surcidal Ideation & $1.06(.24)$ & $1.04(.20)$ & $2.00(.00)$ & $1.41(.49)$ \\
\hline & Mental Status Examination (MSE) & $2,00(.45)$ & $1.66(48)$ & $0.27(.63)$ & $1.24(.94)$ \\
\hline & Personality Styles and Characteristics & $1.51(1.07)$ & $1.84(1.06)$ & $0.21(.81)$ & $1.12(1.21)$ \\
\hline & Psychological Traumas & $1.55(64)$ & $1.52(79)$ & $0.15(60)$ & $1.01(95)$ \\
\hline & Behavioral Observations & $1.37(92)$ & $1.12(.33)$ & $0.08(28)$ & $0.80(.81)$ \\
\hline & Individual Developmental History & $0.86(1.11)$ & $0.10(46)$ & $0.00(.00)$ & $0.30(.77)$ \\
\hline & Psychological Overall & $1.49(.73)$ & $1.28(.56)$ & $1.18(.25)$ & $1.31(.79)$ \\
\hline \multicolumn{6}{|c|}{ Sociocultural } \\
\hline & Relationships & $2.76(.76)$ & $2.72(1.21)$ & $2.65(.87)$ & $2.71(96)$ \\
\hline & Family History & $2.10(.36)$ & $2.22(1.13)$ & $1.76(82)$ & $2.01(85)$ \\
\hline & Employment & $1.84(46)$ & $1.50(1.00)$ & $2.00(.00)$ & $1.80(.64)$ \\
\hline & Education History & $1.88(.38)$ & $1.02(.14)$ & $2.00(.00)$ & $1.66(.49)$ \\
\hline & Legal Issues & $1.69(.68)$ & $1.18(.39)$ & $2.00(.00)$ & $1.65(.55)$ \\
\hline & Current Living Situation/Arrangements & $1.41(.73)$ & $1,40(90)$ & $2.00(.00)$ & $1.63(.70)$ \\
\hline & Financial Resources & $0.45(.86)$ & $1.26(.69)$ & $2.00(.00)$ & $1.29(.89)$ \\
\hline & Religion & $1.47(.54)$ & $1.12(44)$ & $1.00(.00)$ & $1.18(43)$ \\
\hline & Multicultural Issues & $0.88(.59)$ & $1.18(.52)$ & $1,00(00)$ & $1.02(45)$ \\
\hline & Military History & $1.45(.54)$ & $1.00(.00)$ & $0.06(.31)$ & $0.79(.69)$ \\
\hline & $\begin{array}{l}\text { Invohement in Activities of Personal } \\
\text { Interest/Hobbies }\end{array}$ & $0.04(.28)$ & $1.10(.65)$ & $0.00(.00)$ & $0.35(.63)$ \\
\hline & Spirituality & $0.76(.93)$ & $0.14(.41)$ & $0,00(.00)$ & $0.28(.65)$ \\
\hline & Sociacultural Overall & $1.39(.59)$ & $1.32(.62)$ & $1.37(.17)$ & $1.36(.66)$ \\
\hline Biopsycho: & social Overall & $1.41(.17)$ & $1.27(.18)$ & $1.29(.06)$ & $1.32(.15)$ \\
\hline
\end{tabular}

[Citation: Journal/Monograph Title, Vol. XX, No. X (yyyy): pg. XX-XX. DOI. This article is @ [Publisher's Name] and permission has been granted for this version to appear in e-Publications@Marquette. [Publisher] does not grant permission for this article to be further copied/distributed or hosted elsewhere without the express permission from [Publisher].] 
NOT THE PUBLISHED VERSION; this is the author's final, peer-reviewed manuscript. The published version may be accessed by following the link in the citation at the bottom of the page.

\section{Table 5}

Scores on the Overall Use of a Biopsychosocial Approach Scale

\begin{tabular}{|c|c|c|c|c|c|c|c|c|}
\cline { 2 - 9 } \multicolumn{1}{c|}{} & \multicolumn{2}{c|}{ Clinic 1 } & \multicolumn{2}{c|}{ Clinic 2 } & \multicolumn{2}{c|}{ Clinic 3 } & \multicolumn{2}{c|}{ Total } \\
\hline Score & $\boldsymbol{n}$ & $\boldsymbol{\%}$ & $\boldsymbol{n}$ & $\boldsymbol{\%}$ & $\boldsymbol{n}$ & $\boldsymbol{\%}$ & $\boldsymbol{n}$ & $\%$ \\
\hline 0 & 0 & 0.0 & 0 & 0.0 & 0 & 0.0 & 0 & 0.0 \\
\hline 1 & 48 & 96.0 & 35 & 70.0 & 57 & 91.9 & 140 & 85.9 \\
\hline 2 & 3 & 6.0 & 10 & 20.0 & 5 & 8.1 & 18 & 11.0 \\
\hline 3 & 0 & 0.0 & 5 & 10.0 & 0 & 0.0 & 5 & 3.1 \\
\hline 4 & 0 & 0.0 & 0 & 0.0 & 0 & 0.0 & 0 & 0.0 \\
\hline Total & $\mathbf{5 1}$ & $\mathbf{1 0 0 . 0}$ & $\mathbf{5 0}$ & $\mathbf{1 0 0 . 0}$ & $\mathbf{6 2}$ & $\mathbf{1 0 0 . 0}$ & $\mathbf{1 6 3}$ & $\mathbf{1 0 0 . 0}$ \\
\hline
\end{tabular}

[Citation: Journal/Monograph Title, Vol. XX, No. X (yyyy): pg. XX-XX. DOI. This article is @ [Publisher's Name] and permission has been granted for this version to appear in e-Publications@Marquette. [Publisher] does not grant permission for this article to be further copied/distributed or hosted elsewhere without the express permission from [Publisher].] 